\title{
Transkripsiyon metinlerinde Türk atasözleri
}

Beytullah BEKAR1

APA: Bekar, B. (2019). Transkripsiyon metinlerinde Türk atasözleri. RumeliDE Dil ve Edebiyat Araşttrmaları Dergisi, (Ö5), 1-13. DOI: 10.29000/rumelide.606058.

\section{$\ddot{O} \mathbf{z}$}

Türklerin Arap harfleri kullandıkları dönemlerde özellikle Batılı şarkiyatçıların Türkçe öğrenmek ve öğretmek, Türkleri tanımak ve Türkler hakkında bilgi vermek amacıyla Türkçeyi Latin, Grek, Ermeni, Kiril vb. harflerle yazıldıkları eserlere Türkçenin transkripsiyon metinleri denir. Türkçenin transkripsiyon metinleri daha çok İtalyanlar, Almanlar, Fransızlar ve Macarlar tarafindan iki veya çok dilli olarak hazırlanmışlardır. Bu metinler içinde en yaygın sözlükler ve gramer kitapları bulunmaktadır. Sözlüklerin ve gramer kitaplarının içinde atasözleri, Nasreddin Hoca fikraları, konulara göre hazırlanmış karşılıklı konuşma metinleri ve kalıp cümlelere de yer verilmiştir. Bazı transkripsiyon metinlerinin ise sadece atasözü derlemelerinden oluştuğu görülmektedir. $\mathrm{Bu}$ çalışmada, içinde atasözü bulunan transkripsiyon metinleri ve farklı şekilde kullanılan bazı atasözleri incelenmiştir.

Anahtar kelimeler: Türkçe, transkripsiyon metinleri, atasözü, sözlük, gramer.

\section{The Turkish proverbs in transcription texts}

\begin{abstract}
Transcription texts of Turkish are the texts that western orientalists wrote with Latin, Grecian, Armanian, Kiril etc. letters during the times when Turks used Arabic letters in order to learn and teach Turkish, to know more about Turks and to give information about Turks. The transcription texts of Turkish were mostly prepared as bilingual or multilingual by Italians, Germans, French and Hungarians. The most common type of these texts are the dictionaries and grammar books. The dictionaries and the grammar books included proverbs, Nasreddin Hodja jokes, thematically prepared dialogues and idiomatic usages. Some transcription texts consist only of proverbs. In this paper transcription texts which contains proverbs and some proverbs which are being used differently are studied.
\end{abstract}

Keywords: Turkish, transcription texts, proverb, dictionary, grammar.

1 Dr. Öğr. Üyesi, Kırklareli Üniversitesi Fen Edebiyat Fakültesi, Türk Dili ve Edebiyatı Bölümü (Kırklareli, Türkiye), beytullahbekar@gmail.com, ORCID ID: oooo-0002-8372-1190 [Makale kayt tarihi: 19.06.2019-kabul tarihi: 18.08.2019; DOI: $10.29000 /$ rumelide.606058] 


\section{Giriş}

Türkçenin transkripsiyon metinleri Arap harfleri dışında Latin, Ermeni vb. harflerle kaleme alınmış dil öğretim kitapları olmalarının yanında içlerinde bilmeceler ${ }^{2}$, Nasreddin Hoca fikraları3 ${ }^{3}$, ilahiler 4 , şiirler 5 ve atasözleri ${ }^{6}$ barındırmaları nedeniyle Türkoloji çalışmaları için çok önemli kaynaklardır. Çalışmanın kapsamı nedeniyle burada içinde atasözü7 bulunan transkripsiyon metinleri hakkında bilgi verilecektir.

\section{Atasözü ve transkripsiyon metinleri}

Atasözleri bir milletin görüş ve tecrübelerini en güzel yansıtan sözlü kültür ürünlerindendir. Çıktıkları toplumların düşünce yapısını, örf ve âdetlerini yansıtmakla birlikte bir kültür mirasıdırlar. Bir millet hakkında bilgi sahibi olmak isteyenler aynı zamanda o toplumun atasözlerini derlemişler, kendi dillerine aktarmışlar ve anlamaya çalışmışlardır. Yapılan araştırmalarda yabancılar tarafından Türk atasözlerinin Arap harfleri dışında en yaygın Latin harfleriyle kaleme alındıkları görülmektedir. Bununla birlikte Ermeni harfleriyle de kaleme alınan atasözleri vardır ${ }^{8}$. Ermeni harfleriyle verilmiş atasözleri çalışmamızın dışında tutulmuş olup burada Latin harfleriyle kaleme alınmış transkripsiyon metinlerinde geçen atasözleri hakkında bilgi verilmekle yetinilmiştir. Latin harfleriyle kaleme alınmış kimi çalışmalar müstakil atasözlerinden oluşmuşken kimi çalışmalarda atasözleri gramer kitaplarının içinde ayrı bir başlık halinde veya gramer kurallarına örnek cümleler olarak verilmiştir. En eskisi 16. yüzylla dayanan bu çalışmaların 17., 18. ve 19. yüzyılda arttığı görülmektedir.

\subsection{On altıncı yüzyıl}

\subsubsection{Georgieuiz, B. (1544). De Tvrcarvm Ritv Et Caeremoïs. Antverpia.}

Bartholomeo Georgieuiz’in ilk eseri De Turcarum Ritu Et Ceraemoniis, kırk altı sayfadan oluşan küçük hacimli bir kitapçıtır. De Turcarum Ritu Et Ceraemoniis'ta Türklerin dini, günlük yaşamları ve orduları hakkında bilgiler bulunur. Son bölümünde Türkçe - Latince sözlük vardır. Ayrıca Türkçe selamlaşma cümleleri, sayılar, gramer kuralları, bir Türk ile Hristiyan arasında geçen kısa bir konuşma metni de bulunmaktadır. Eserde atasözleri derlemesi bulunmasa da metin içinde bir durumu açıklamak için Türklerin kullanmış olduğu bir atasözüne yer verilmiştir. İlk olarak 1544 yılında ayrı bir basımı yapılan kitapçık daha sonra De Turcarum Moribus Epitome 'Türklerin Kişiliği Üzerine Yazılar' adlı kitabın içinde bir bölüm olarak basılmaya başlanmıştır (Aksulu 1998: 11-12).

2 Bakınız: Argunşah, M. ve Güner, G. (2015). Codex Cumanicus. İstanbul: Kesit.

3 Bakınız: Müller A. (1889). Türkische Grammatik mit Paradigmen Litteratur Chrestomathie und Glossar. Berlin: H. Reuther's Verlagsbuchhandlung.

4 Bakınız: Megisero, H. (1612). Institutionum linguae turcicae, libri quatuor. Quorum I. continet partem isagoges grammaticae Turcicae priorem, de orthographia Turco-Arabica. II. verò isagoges grammaticae Turcicae partem, poeteriorem, de etymologia Turcorum. III. complectitur diversa linguae Turcicae exercitia, \& duas proverbiorum Turcicorum centurias. IV. Dictionarium est Latino Turcicum \& vicissim Turcico Latinum. Lipsiae (Leipzig): Magiserus.

5 Bakını: Wickerhauser, M. (1853). Wegweiser zum Verständnis der türkischen Sprache. Eine deutsch-türkische Chrestomathie. Wien: K.K. Hof-und Staatsdruckerei.

Schlechta Wssehrd, O. F. von (1865). Osmanische Sprichwörter. Wien: K.K. Orientalische Akademie.

İncelemiş olduğumuz eserlerde atasözleri Proverb, Proverbia, Sprichwörter, Zarbi mesel, Proverbiis gibi başlıklar altında verilmiştir. Fakat bazı yazarlar atasözleri başlı̆̆ı altında birkaç deyimi de "Yer demir, gök bakır" gibi atasözü kabul ederek vermişlerdir.

8 Ermeni harfli atasözleri çalışmaları için bakınız: Kut, T. (1983). Ermeni Harfleriyle Basılmış Türkçe Atasözleri Kitapları. Türk Folkloru 53/5 ss. 5-6; Kaymaz, Z. (2013). Ermeni Harfli Bir Türkçe Atasözleri Kitabı. Türk Dünyası İncelemeleri Kitabı XIII/1 ss. 173-212; Yıldız, H. ve Öztürk Abdulkadir (2016). 19. Yüzyıla Ait Ermeni Harfli Türkçe Atasözleri Üzerine. ODÜ-SOBIAD 6 (3) ss. 739-766. 


\subsection{On yedinci yüzyıl}

2.2.1. Megiser, H. (1605). Polyglottos: hoc est: Proverbia et Sententiae complurium linguarum. Ex Sacris Videlicet Hebraeorum fontibus, atq; ex optimis ac probatiffimis quibusq; Graecae \& Latinae linguae fcriptoribus, defumtae, \& in Locos Communes digeftae: \& cum Italorum, Hifpanorum, Gallorum, Germanorum, Belgarum, Sclavonum, Arabum, Turcarum denique aliarumq; Nationum fententio/is Proverbiis collatae. Lipsiae (Leipzig): Sumtibus Henningis Grosii.

Megiser’in atasözü bilimi için son derece önemli olan Paroemiologia Polyglottos... 240 sayfadan oluşan çok dilli, konulara göre hazırlanmış bir atasözü derlemesidir. Eserin ilk baskısı 1592 yılında Graz'da yapılmıştır. Bu baskıda Yunan ve Latin harfleriyle Yunan ve Latin şairlere ve filozoflara ait özdeyişler ile İtalyan, Galya, Alman ve diğer Hristiyan halklarının atasözleri verilmiştir. 1605 yılında yapılan baskıda ise 1592 yılındaki baskıya ilave olarak İbrani alfabesiyle yazılmış kutsal Yahudi metinleri ile İspanyollara, Belçikalılara, Slovenlere, Araplara ve Türklere ait atasözleri bulunmaktadır. Bu baskıda diğer bir farklılık ise Hristiyan halkları ibaresindeki dinî sıfatın kaldırılmış olmasıdır (Durmuş 2017: 662). Paroemiologia Polyglottos'ta Latin harfleriyle yazılmış toplam 99 atasözü bulunmaktadır. Burada geçen atasözlerinden bazıları 1612 yılında yayımlanan gramer kitabında tekrar verilmiştir. Paroemiologia Polyglottos'taki atasözlerinin Türkçenin basılı ilk atasözleri örnekleri olması bakımından son derece önemlidir (Durmuş 2017: 663).

2.2.2. Megiser, H. (1612). Institutionum linguae turcicae, libri quatuor. Quorum I. continet partem isagoges grammaticae Turcicae priorem, de orthographia Turco-Arabica. II. verò isagoges grammaticae Turcicae partem, poeteriorem, de etymologia Turcorum. III. complectitur diversa linguae Turcicae exercitia, \& duas proverbiorum Turcicorum centurias. IV. Dictionarium est Latino Turcicum \& vicissim Turcico Latinum 9 . Lipsiae: Magiserus.

Megiser’in Türkoloji için 'Paroemiologia Polyglottos...' adıyla bilinen atasözü çalışması kadar önemli çalışmalarından biri de Institutionum linguae turcicae, libri quatuor... adlı eseridir.

Eser, 375 sayfa ve 4 bölümden oluşmaktadır. 1. bölümde eski yazı ve Türkçe telaffuz üzerinde durulur. $\mathrm{Bu}$ eserde kullanılan Arapça kalıplar Breslau'da Peter Kirstein tarafından hazırlanır. Bu kalıplar Almanya'daki ilk Arapça kalıplardır. Megiser'in, kitabının 2. bölümünde gramerle ilgi bilgiler verilmiştir. 3. bölümde, 220 atasözü vardır. Stein'a göre bu atasözlerinden bazıları Türkçeye başka dillerden geçmiştir. 4. bölümde ise 2500 Türkçe sözcüğün yer aldığı Latince-Türkçe / Türkçe-Latince sözlük vardır (Gül 2006: 61).

Eserde Latin harfleriyle yazılmış toplam 241 atasözü bulunmaktadır. 220’si atasözleri başlığı altında, geri kalan 21’i ise eserin baş tarafındadır.

2.2.3. Montalbano, G. B. (1632). Turcicae linguae per terminos latinos educta Syntaxis in usum eorum qui in Turciam missiones subeunt ad nutum sacrae congregationis de propoganda fide. İtalya: Napoli Milli Kütüphanesii1.

9 Eser için bundan sonra 'Institutionum linguae turcicae' kısaltması kullanılacaktır.

10 Bu eserdeki atasözleri Aldo Gallotta’nın 1986 tarihinde İstanbul Üniversitesi Türk Dili ve Edebiyatı Dergisinin XXIV. sayısında yayımlamış olduğu "Latin Harfleri ile Yazılmış Bir Kaç Osmanlı Atasözü” adlı makalesinden alınmıştır. Aldo Gallotta, makalesinde eserin yazllma tarihini Leone Allacci'nin 1632 olarak belirtmesine rağmen 1622 - 1632 tarihleri arası olarak vermiştir. Biz çalışmamızda Leone Allacci’nin belirtmiş olduğu tarihi esas alarak eserdeki atasözlerini 1632 olarak tarihlendirdik. 
Montalbano, Papa XV. Gregorio'nun emri ile 1622 yllında kurulan De Propaganda Fide kongregarisyonun isteği doğrultusunda Turcicae Linguae per Terminos Latinos Educta Syntaxis in Usum Eorum Qui in Turciam Missiones Subeunt adlı eseri yazmıştır. Leone Allacci'nin verdiği bilgiye göre eser 1632 yllında yazılmıştır. Eser 225 sayfa olup üç bölümden oluşmaktadır: 1. bölümde gramer bilgileri (3a-8ob), 2. bölümde Türkçe-Latince sözlük ( $81 \mathrm{a}-211 \mathrm{~b}), 3$. bölümde ise atasözleri (212a 225a) vardır (Gallotta 1986: 235-236). Atasözleri Latin harfleriyle ve alfabe sırasına göre sıralanmış olup 144 tanedir.

2.2.4. Hrabskius, J. (1655). Proverbia quaedam Arabica, Persica, \& Turcica: In Gratiam Praedictarum Linguarum Cultorum Edita (Editör: Fincelius, Hiob Wilhelm). Witteberg: Wilhelm Fincelius ${ }^{11}$.

Eser, 16 sayfa olup bir atasözü derlemesi şeklinde hazırlanmıştır. İçinde 8 Arap, 10 Fars ve 10 Türk olmak üzere toplam 28 atasözü mevcuttur. Toplam eserin hacminden de anlaşlacağı üzere kitapta fazla sayıda atasözü yoktur. Nicelik açısından çok büyük bir değeri olmasa da salt atasözlerini konu edinmiş bir eser olması bakımından bu alandaki ilklerden sayılır. Eserde yer alan 10 Türk atasözü Arap harfleriyle yazılmış ve atasözlerinin altında Latince tercümeleri verilmiştir.

2.2.5. Francesco, M. M. (1670). Syntagmaton Linguarum Orientalium quae in Georgiae regionibus audiuntur liber primus, complectens Georgianae, seu Ibericae vulgaris linguae institutiones grammaticas.: (with) Liber secundus complectens Arabum et Turcarum orthographiam ac Turcicae linguae institutiones. Roma: Stamperia della Sacra Congregazione de Propaganda Fide.

Eser iki cilt halinde hazırlanmıştır. 1. cilt 1643 yılında yazılmış ve 145 sayfadır. Bu ciltte Gürcücenin grameri kakkında detaylı bilgi verilmiştir. 2. cilt ise 1670 yılında yazılmış ve 96 sayfadır. 2. ciltte Türkçe ve Arapçanın imlâ özellikleri ve Türkçenin gramer kuralları verilmiştir (İğci 2014: 32). Bu eserdeki atasözleri diğer eserlerden farklı olarak atasözleri başlığı altında değil, 68. sayfadan itibaren gramer kuralları anlatılırken gramer kurallarına uygun örnekler olarak verilmiştir. Eserde 96'sı Arap ve Latin harfli, 14’ü de yalnız Arap harfli olmak üzere 110 atasözü tespit edilmiştir.

2.2.6. Harsany, Jacobus Nagy de (1672). Colloquia Familiaria Turcico Latina Seu Status Turcicus Loquens. Coloniae Brandeburgicae.

Eser; giriş, karşılıklı konuşma metinleri, dizin (index) ve vasiyetname (testamentum) bölümlerinden oluşmaktadır. Söz başı özelliğindeki giriş bölümü 10 sayfadır. Sonrasında diyalogların bulunduğu ana kısım gelir. Karşılıklı konuşma metinleri toplam 510 sayfadır. Dizin bölümü 25 sayfadır. Vasiyetname bölümü de 10 sayfadır. Bütün bu alt bölümlerinin tamamıla Colloquia Familiaria Turcico-Latina toplam 555 sayfadır. Bir gramer kitabı veya sözlük olmayan eserin yazarının temel amacı Türkçeyi, Osmanlı toplumunun birçok özelliğini karşılıklı diyaloglarla Osmanlı İmparatorluğu dünyası dışındaki okurlara öğretmektir (İğci 2015: 72). Eserin ilk sayfasında atasözü başlığı altında 1 atasözü ve Latince tercümesi verilmiştir.

11 Bu eserdeki atasözleri Oğuzhan Durmuş’un 2018 yllı Şubat’ta Türk Dili dergisinde çıkan '1655 Tarihli Küçük Bir Atasözü Derlemesi: Proverbia Quaedam Arabica, Persica, \& Turcica'daki Türk Atasözleri’ adlı makalesinden alınmıştır. Durmuş, makalesinde eserde 10 Türkçe atasözü var demesine rağmen 9 atasözü vermiştir. Numaralandırmada 3 numaralı atasözünden 5 numaralı atasözüne geçilmesi, 4 numaralı atasözünün ‘Er ölür ad ḳalur’ unutulmuştur. 
2.2.7. Timoteo, A. (1688). Proverbii utili, e virtuosi in lingua araba, persiana, e turca, gran parte in versi, con la loro ispiegatione in lingua latina, \& italiana et alcuni vocaboli di dette lingue. In Padova: Nella Stamperia del Seminario.

Eser, küçük bir broşür niteliğinde olup toplam 82 sayfadan oluşmaktadır. Avrupa'da Türk atasözlerine ait en eski derlemelerden biridir. Bu eserde Türk atasözleri ve vecizelerinin yanında (ss. 22-33) aynı cinsten Arapça ve Farsça metinler de bulunmaktadır. Atasözleri her bir sayfada iki sütun halinde, çift rakamlı sayfalarda Arap ve Latin harfli verilmiştir. Tek rakamlı sayfalarda ise yine iki sütun halinde İtalyanca ve Latince tercümele vardır. Atasözleri ve veciz sözlerin Agnellini tarafından mı derlendiği veya başka bir eserden mi aktardığı konusu meçhuldür. Türk atasözlerinden oluşan sütunun başlı̆̆ının Arapça olması, Agnellini'nin bu konuda bir Arap müellifin eserinden yararlandığını akıllara getirmektedir (Drimba 1985: 9-10). Eserde Arap ve Latin harfleriyle yazılmış 38 atasözü bulunmaktadır.

2.2.8. Donado, G. B. (1688). Della Letteratura de' Turchi, Osservationi fatte da Gio. Italia: per Andrea Poletti. all'insegna dell'Italia, a San Marco.

Eser, Lo Stampatore A Chi Legge başlıklı 9 sayfalık girişten sonra eserin adı, yazarı ve unvanları (Senator Veneto, Fu Bailo Coftantinopoli) belirtilen başlıkla eser başlar. Bu transkripsiyon metni Türkler hakkında çeşitli alt başlıklarda anlatılan bilgi ve gözlemler içerir ve $148(140+8)$ sayfadan oluşur. Eser 140 sayfa numarasıyla son bulur. Sonrasında, alt kısmında transkripsiyon işaretleriyle yazılmış Türkçe sözler içeren 8 sayfalık nota cetveli yer alır. Bu bir müzik eserinin (şarkı vb.) örneğidir (İ̆gci 2014: 38).

Della Letteratura de Turchi'de iki farklı yerde transkripsiyon işaretleriyle kaydedilmiş Türkçe atasözleri ve deyimler bulunmaktadır. 97-100 sayfaları arasında birkaç Türkçe atasözü ve tercümesi yapılmıştır. 137 ile 139 sayfaları arasında da transkripsiyon işaretli Türkçe sözler, altında İtalyanca tercümesi verilmiş olan deyimler vardır (İğci 2014: 38). Eserdeki Latin harfli atasözü sayısı 12'dir.

2.2.9. Donado, G. B. (1688). Raccolta curiosissima d'Adaggi Turcheschi trasportati dal proprio Idioma nell Italiano e Latino dalli Giovani di Lingua, sotto il Bailaggio in Constantinopoli dell' illustriss ed eccell. Italia: Per Andrea Poletti all' Italia.

Eser, 87 sayfadır. Eserde askerlik, ekonomi, ahlak, kutsal ve din, gülünç ve yergi olmak üzere 7 konu başlığı altında 397 atasözü verilmiştir. Eserin çift rakamlı sayfalarında Arap ve Latin harfli yazılışları, tek rakamlı sayfalarında İtalyanca ve Latince tercümeleri vardır.

2.2.10. ? (1689?). "Proverbia turcica cum versione italica et latine" \& "Iterum Proverbia turcica, quorum major pars latinis literis scripta est”. (Eserin sahibi: Moritz Georg Weideman)

Bu eser Dresden Kütüphanesi Mscr.Dresd.Ea.224 numarada kayıtlı bir mecmuadır. Atasözleri ise bu mecmuanın içindedir. Mecmuanın müstensihi bilinmemektedir. Kütüphane kataloğunda mecmua, Moritz Georg Weideman (1686-1743) adına kayıtlıdır. Mecmuanın dilinin Farsça ve Türkçe olduğu belirtilmektedir. Mecmua içinde $68 \mathrm{~b}$ - 92a varakları arasında "Proverbia turcica cum versione italica et latine" ve 102b - 111a varakları arası "Iterum Proverbia turcica, quorum major pars latinis literis scripta est” başlıkları altında iki ayrı yerde biri Arap diğeri Latin harfli olmak üzere atasözleri verilmiştir. 68b - 92a varakları arasındaki atasözleri Arap harfleriyle yazılmış sonraki sayfada iki sütun halinde Latince ve İtalyanca tercümeleri verilmiştir. 102b - 111a varakları arasında ise atasözleri Latin harfleriyle verilmiştir. H. L. Fleischer, 1831 yllında hazırlamış olduğu Catalogus Codicum Manuscriptorum Orientalium Bibliothecae Regiae Dresdensis adlı eserinde mecmuadan hareketle bu isimlendirmeleri 
yapmıştır. Mecmua, XII + $111+19$ sayfadır. Kütüphane kayıtlarında mecmuanın tarihi yaklaşık 1689 olarak verilmiştir. Fakat mecmua içinde bir mukataa kaydında H.1068 (M. 1658) tarihi geçmektedir. Hazai (1982: 264), yazmanın sahibinin Moritz Georg Weideman (1686 - 1743) olduğunu belirtir. Hazai makalesinde yazmanın tahmini olarak 1689 ile 1728 tarihleri arasında yazılmış olabileceğini fakat 102b - 111a varakları arasındaki atasözlerinin diğer bölümlere göre daha geç dönemde ve Moritz Georg Weideman tarafından yazılmış olabileceğini belirtir. Hazai, 1982 yılında yayımlanan makalesinde 102b - 111a varakları arasındaki Latin harfli atasözlerini tanıtmış, eser hakkında kısa bilgi vermiş fakat 68b 92a varakları arasında bulunan Arap harfli atasözlerini işlememiştir. Mecmua içinde 388'i Arap ve 218'i Latin harfli olmak üzere 606 atasözü bulunmaktadır.

\subsection{On sekizinci yüzyıl}

2.3.1. Vaughan, T. (1709). A Grammar Of The Turkish Language. London: Publisher, J. Humphreys.

A Grammar Of The Turkish Language adlı eser Thomas Vaughan tarafından İzmir'de hazırlanmış ve 1709 yılında Londra'da basılmıştır. 103 sayfa olup 21 bölümden oluşmaktadır. İlk 17 bölümde Türkçenin grameri hakkında bilgi vardır. 18. bölümde karşllıklı konuşma metinleri, 19. bölümde fabl, 20. bölümde 53 atasözü ve son bölümde İngilizce - Türkçe küçük bir sözlük bulunmaktadır. Atasözlerinden önce verilen fablda, yazar çıkarılması gereken ders olarak “Az tamah, çok ziyan” atasözünü vermiştir. Bununla birlikte eserdeki atasözü sayısı 54 etmektedir. Atasözleri (ss. 71-76) alfabetik sıraya göre her bir sayfada iki sütun halinde Latin harfleriyle verilmiş karşılarına da İngilizce tercümeleri yazılmıştır.

2.3.2. Clodius, J. Ch. (1729). Grammatica Turcica Necessariis regvlis praecipvas lingvae difficvltates illvstrans (etc). Lipsiae: Wolffgangvm Deer.

Cloudius'un 1729 yllında hazırlamış olduğu Türkçenin gramerinin anlatıldığı Grammatica Tvrcica Necessariis regvlis praecipvas lingvae difficvltates illvstrans (etc) ile 1730 yllında Latince, Almanca ve Türkçe olmak üzere üç dilli hazırlamış olduğu Compendiosum Lexicon LatinoTurcico-Germanicum (1730) adlı sözlüğü Türkoloji için çok önemlidir. Grammatica Tvrcica Necessariis regvlis praecipvas lingvae difficvltates illvstrans (etc) adlı eserin ilk 87 sayfasında gramer bilgileri verilmiştir. 88-106 sayfalar arasında Latin ve Arap harfli Türkçe metinler ve bunların incelenmesi vardır. 107-167 sayfalar arasında yine Latin harfli Türkçe ve Latince karşıllklı konuşma metinleri bulunmaktadır. 168-179 sayfalar arasında karşılıklı konuşma metinlerinde geçen bazı kelime ve kelime grupları hakkında açıklamalar yapılmıştır. 180- 192 sayfalar arasında Latin ve Arap harfli 31 atasözü ve bunların kelime kelime Latinceye tercümesi bulunmaktadır.

2.3.3. Preindl, J. von (1789). Grammaire Turque: D'une toute nouvelle methode d'apprendre cette langue en peu de semaines avec un vocabulaire. Berlin.

Grammaire Turque'ün ilk baskısı 1787 yılında 2. baskı 1789'da, 3. baskı 179o'da ve 4. baskı da 1791'de Berlin'de yapılmıştır. Eser Prusya Kralı II. Frederic Guillaume'a takdim edilmiştir. Eser 10 bölüm halinde ve her bölümü paragraflar şeklinde düzenlemiş, kendisine göre bir konu sırası belirlemiştir. 17 bölümlerde gramer kuralları, 8. bölümde soru cevaplarla hazırlanmış karşılıklı konuşma metinleri, 9 . bölümde Hatayi'den bir alıntı, bir deyim ve 38 atasözü bulunmaktadır. 10. bölümde ise 6 adet fabl vardır (Yılmaz - Demirci 2016: 10-11). Atasözleri Latin harfleriyle yazılmış olup altında Fransızca tercümesi ve yazarın atasözü ile ilgili yine Fransızca yorumu bulunmaktadır. 
2.3.4. Pianzola, B. (1789). Dizionario, Grammatiche, e Dialoghi Per Apprendere le Lingue Italiana, Greca-Volgare, e Turca, e Varie Scienze. Podova: Fermo.

Dizionario, Grammatiche, e Dialoghi Per Apprendere le Lingue Italiana, Greca-Volgare, e Turca, e Varie Scienze adlı eser üç cilt halinde hazırlanmıştır. Eserin 1. cildi (ss. 1-112) İtalyanca, Yunanca ve Türkçe sözlüktür. Bu sözlükte, her bir sayfada iki sütun halinde kelimenin İtalyancası, Yunancası ve Türkçesi verilmiştir. 2. cilt de (ss. 1-48) sözlük olup yalnızca İtalyanca ve Yunanca kelimelerden ibarettir. İtalyanca ve Yunanca sözlük her bir sayfada üç sütun halinde hazırlanmıştır. 3. cilt (ss. 1-164) dört bölüm halindedir. 1. bölümde (ss. 1-9) alfabe ve bazı harflerin telaffuzları, 2. bölümde (ss. 9-43) gramer kuralları, 3. bölümde (ss. 43-49) cümle yapıları ve 4. bölümde (ss. 50-164) darbımeseller (zerbimefeller), atasözleri (atalar dei(cileri) ve değişik konularda hazırlanmış karşılıklı konuşma metinleri (mukameller) vardır. 224 atasözü (ss. 60-68) her bir sayfada üç sütun halinde Latin harfli, İtalyanca ve Yunanca tercümeleriyle verilmiştir.

\subsection{On dokuzuncu yüzyıl}

2.4.1. Dombay, F. von (18.yy?). Proverbiorum Turcicorum Centuria I-IV \& Proverbia Turcica Quadraginta. İngiltere: Manchester John Rylands Kütüphanesi.

Dombay'ın Türkçe atasözleri ve deyimler derlemesinde Arap harfli toplam 440 atasözü ve özlü söz kayıtlıdır. Bunlar, dördü 100, biri 40 sözü içeren beş bölüm hâlinde gruplanmış ve ilk harflerine göre alfabetik olarak sıralanmıştır. Her sayfada beş söz yer almakta, ve her sözün yanında Latince tercümesi de bulunmaktadır (Ekinci 2013: 56). Jan Schmidt (2011: 303-307) A Catalogue of the Turkish Manuscripts in the John Rylands University Library at Manchester adlı çalışmasında Persian 141'de kayıtlı yazmanın Franz von Dombay adına kayıtlı olduğunu, bu eserin 8 bölümden oluştuğunu ve ilk bölümün Franz von Dombay tarafından kaleme alındığını diğer 7 bölümün ise Levinus Warner’in (16191665) eserinden kopya edildiğini belirtmektedir. Fakat Ekinci, çalışmasında J. Schmidt’in belirttiği kataloglarda yapmış olduğu incelemede bu bilginin doğru olmadığını ifade eder (2013: 56). Eserin yazım tarihi tam olarak bilinmemekle birlikte 18. yüzyılın sonlarına doğru yazıldığı tahmin edilmektedir ${ }^{12}$.

2.4.2. Jaubert, P. A. (1823). Elements de la grammaire turke. Paris: Dundey-Dupre Pere et Fils.

Elements de la grammaire turke adlı eserin iki baskısı mevcuttur. 1. baskısı Paris'te Imprimerie Royal'de 1823'te, atasözlerini aldığımız 2. baskısı ise aynı yerde 1833 yılında basılmıştır. Eser 429 sayfa olup 5 bölüm olarak hazırlanmıştır. 1. bölümde (ss. 17-228) gramer bilgileri, 2. bölümde (ss. 229-265) karşıllklı konuşma metinleri, 3. bölümde (ss. 267-334) sözlük, 4. bölümde (ss. 335-377) Arap harfli ve Fransızca tercümleri bulunan 358 atasözü, 5. bölümde (ss. 378-429) değiş̧ik konularda yazılmış Arap harfli Türkçe metinler ve Fransızca tercümeleri ile bazı metinlerin Uygur harfli örnekleri bulunmaktadır.

2.4.3. Hindoglu, A. (1829). Theoretisch=pracktische Türkische Sprachlehre für Deutsche. Wien: Anton Edler v. Schmid.

Theoretisch = pracktische Türkische Sprachlehre für Deutsche adlı eser i+ii+178+[2] sayfadan oluşmaktadır. Eserin 1. bölümünde (ss. 1-84) gramer bilgisi, 2. bölümünde (ss. 86-93) değişik konularda

12 Derlemede verilen atasözleri ve eser hakkında geniş bilgi için bakınız: Ekinci, M.U. (2013). Franz von Dombay’ın (17581810) Türkçe Atasözleri ve Deyimler Derlemesi. Türkbilig. 2013/25 ss. 55-74; Jan Schmidt (2011), A Catalogue of the Turkish Manuscripts in the John Rylands University Library at Manchester, ss. 303-307, Leiden: Brill. 
kullanılan kelimeler ve kelime grupları, 3. bölümünde (ss. 94-110) her bir sayfada üç sütun halinde hazırlanmış Arap ve Latin harfli Türkçe karşılıklı konuşma metinleri ve Almanca tercümeleri verilmiştir. Bu bölüm içinde 107. sayfada 13 atasözü "Zarbi mesel - Sprüchwörter" bulunmaktadır. Karşıllklı konuşma metinlerinin ardından (ss. 111-178) alfabetik olarak yine üç sütun halinde Latin harfli Türkçe ve Almanca sözlük vardır.

2.4.4. Wickerhauser, M. (1853). Wegweiser zum Verständnis der türkischen Sprache. Eine deutschtürkische Chrestomathie. Wien: K.K. Hof-und Staatsdruckerei.

Eser iki cilt ve her bir cilt on altı bölüm halinde hazırlanmıştır. 1. ciltte Arap harfli Türkçe metinler ve şiirler, 2. ciltte birinci ciltteki metinlerin Almanca tercümeleri vardır. Kitabın Arap harfli Türkçe bölümü 328, Almanca bölümü ise $\mathrm{X}+347+$ [3] sayfadan oluşmaktadır. Eserdeki 517 atasözü Arap harfli olup birinci bölümde (ss. 1-10) bulunmaktadır.

2.4.5. Fleischer, H.F. (1853). Der vollkommene und schnelle türkische Selbstlehrer. Wien: Albert A. Wenedikt Verlag.

Eser, $146+$ [2] sayfadan oluşmaktadır. Dört bölüm halinde hazırlanmıştır. 1. bölümde (ss. 1-66) Türkçenin grameri, 2. bölümde (ss. 67-86) her bir sayfada değişik konularda üç sütun halinde hazırlanmış Arap ve Latin harfli Türkçe ve Almanca tercümeleriyle karşıllklı konuşma metinleri, 3 . bölümde (ss. 87-101) atasözleri ve 4. bölümde (ss. 102-146) konulara göre hazırlanmış üç sütun halinde Türkçe kelimelerin hem Latin hem Arap harfli şekiller verilmiş karşılarına da Almancaları yazılmıştır.

Eserde atasözleri iki farklı şekilde verilmiştir. 87-88 sayfalar arasında üç sütun halinde Arap ve Latin harfli 21 atasözünü ve Almanca tercümeleri, 90-101 sayfalar arasında Arap harfli 113 atasözü ve Almanca tercümeleri vardır.

2.4.6. Mallouf, N. (1860). Guide en trois langues: Française, anglaise at Turque. Paris: Maisonneuve et Ce.

Eser, XXIII $+[1]+201+[5]$ sayfadan oluşmaktadır ve Fransızca, İngilizce ve Türkçe olmak üzere üç dilde hazırlanmıştır. Kitap beş bölümden oluşmaktadır. 1. bölümde (ss. 2-43) en gerekli 170 kelime, renk adları, gün adları ve sayılar hakkında bilgiler verilmiştir. 2. bölümde (ss. 44-71) kalıp cümle türleri, 3 . bölümde (ss. 72-175) karşllıklı konuşma metinleri, 4. bölümde Arap ve Latin harfli (ss. 177-183) 25 atasözü ve Fransızca ile İngilizce tercümeler vardır. 5. bölümde (ss. 184-201) değişik konularda örnek alınabilecek kısa mektup örnekleri bulunmaktadır ${ }^{13}$.

2.4.7. Schlechta Wssehrd, O. F. von (1865). Osmanische Sprichwörter. Wien: K.K. Orientalische Akademie.

Eser XIV + [2] + 180 sayfadır. Atasözleri (ss. 2-155) her bir sayfada iki sütun halinde hazırlanmıştır. Çift rakamlı sayfalarda atasözlerinin Almanca ve Fransızca tercümeleri, tek rakamlı sayfalarda ise Arap harfli yazılışlarıyla birlikte Almanca ve Fransızcanın ses denkliğine göre Latin harfli olarak Türkçe şekilleri verilmiştir. Ayrıca yazar, Arap harfli atasözlerinin altına kelime kelime Almanca ve Fransızcalarını da vermiştir. Atasözlerinden sonra (ss. 159-180) sözlük bulunmaktadır. Sözlük, her bir

13 Bu eser Ceylan Doğan tarafindan yüksek lisans tezi olarak çalışılmaktadır. 
sayfada iki sütun halinde alfabetik olarak önce Arap harfli ardından da Almanca ve Fransızca tercümesiyle hazırlanmıştır. Eserde toplam 500 atasözü bulunmaktadır.

2.4.8. Piquere, P. J. (1869) Grammatik der türkisch-osmanischen Umgangssprache. Wien: Albert A. Wenedikt Verelag.

Eser VIII $+344+$ [12] sayfa olup ön söz ve dört bölümden oluşmaktadır. 1. bölümde (ss. 1-257) Türkçenin gramer bilgileri, 2. bölümde (ss. 258-286) karşllıkl konuşma metinleri, 3. bölüme (ss. 287303) toplam 346 atasözü, deyimler ve özlü sözler, 4. bölümde (ss. 304-344) alfabetik olarak hazırlanmış sözlük vardır. Ayrıca sözlüğün sonuna içindekiler ve doğru yanlış cetveli konulmuştur.

Eserdeki atasözleri iki bölüm halindedir. 1. bölümde (ss. 287-298) her bir sayfada iki sütun halinde atasözleri Arap harfli ve yanlarında Almanca tercümeleri vardır. 2. bölümde ise (ss. 299-303) yine her bir sayfada iki sütun halinde atasözlerinin Latin harfli şekilleri bulunmaktadır.

2.4.9. Wahrmund, A. (1869). Praktisch Handbuch der osmanisch-türkischen Sprache I-III. Giessen: J. Ricker'sche Buchhandlung.

Eser üç cilt olarak hazırlanmış ve toplam 637 sayfadan oluşmaktadır. Eserin üç cildi de 1869 yllında Giessen'de basılmıştır. 1. cilt 420 sayfadır ve Türkçenin gramer bilgilerini içerir. 2. cilt 139 sayfa olup iki bölümden oluşmaktadır. 1. bölümde konulara göre hazırlanmış sözlük vardır. 2. bölüm ise kendi içinde iki alt bölümden oluşmuştur. 1. alt bölümde konulara karşllklı konuşma cümleleri, 2. alt bölümde ise Arap harfli 100 atasözü bulunmaktadır. 3. cilt 78 sayfa olup bir cevap anahtarı niteliğindedir. 3. ciltte 2. ciltteki Arap harfleriyle verilmiş atasözlerinin, Nasreddin Hoca fikralarının ve Osmanlı İmparatorluğu ile İngilizler arasında imzalanan anlaşma metninin Latin harfli şekli verilmiştir.

2.4.10. Fink, L. (1872). Türkischer Dragoman, Grammatik, Phrasensammlung und Wörterbuch der türkischen Sprache. Leipzig: F.A. Brockhaus Verlag.

Eser, VI + 162 sayfa olup dört bölüm halinde hazırlanmıştır. 1. bölümde (ss. 1-78) Türkçenin grameri hakkında bilgi, 2. bölümde (ss. 79- 144) her bir sayfada iki sütun halinde konu siralı ve Latin harfli Almanca - Türkçe (ss. 79-117) ve Türkçe - Almanca (ss. 118-144) iki sözlük, 3. bölümde (ss. 145-160) bazı konularda hazırlanmış Latin harfli ve Almanca tercümeleriyle birlikte karşılıklı konuşma metinleri, 4. bölümde ise (ss. 161-162) Latin harfli 20 atasözü ve Almanca tercümesi bulunmaktadır.

2.4.11. Müller, A. (1889). Türkische Grammatik, mit Paradigmen, Litteratur, Chrestomathie, und Glossar. Berlin: H. Reuther.

Eser, toplam XIV + 136 sayfa olup beş bölüm olarak hazırlanmıştır. 1. bölümde (ss. 1-130) Türkçenin grameri hakkında bilgi, 2. bölümde (ss. 1-39) isim ve fiil çekimleri örnekleri, 3. bölümde (ss. 41-55) Osmanlı tarihi, edebiyatı, dili vb. konularda yabancı ve Türkler tarafından hazırlanmış kaynakların künyeleri verilmiştir. 4. bölümde Arap harfleriyle yazılmış 137 atasözü, 5. bölümde her bir sayfada iki sütun halinde, alfabetik, Almanca ve Fransızca tercümeleriyle birlikte Arap ve Latin harfli Türkçe kelimelerin verildiği sözlük vardır. 


\section{Eserlerdeki bazı atasözlerinde görülen farklılıklar}

Örnek 1.

(1612) Can eile canon eileme. Kan eyle, kanon eyleme.

(1632) Can eyle canon eileme. Kan eyle kanon eyleme.

(1670) Ḳan eyle ḳānūn eyleme.

(1688) Kan eyle kāanun eyleme // Can eile canun eileme. Kan eyle, kanun eyleme.

(1689?) Ḳan eyle kạ̄nūn eyleme.

(1729) Ḳan eyleme kānūn eyle // Kan eilme, kanun eile. Kan eylme, kanun eyle.

(1789) Kan eyleme, kanoun eyle. Kan eyleme, kanun eyle.

(18.yy?) Ḳan eyleme, ḳānūn eyle.

(1823) Kạn eyleme ḳānūn eyle.

(1853) Ḳan eyleme ḳānūn eyle.

Atasözü; Megiser, H. (1612). Institutionum linguae turcicae libri quatuor..., Montalbano, G. B. (1632). Turcicae linguae per terminos..., Francesco, M. M. (1670). Syntagmaton Linguarum Orientalium..., Donado, G. B. (1688). Raccolta curiosissima d'Adaggi Turcheschi trasportati... ve ? (1689?). "Proverbia turcica cum versione italica et latine"... adlı eserlerde "Kan eyle, kanun eyleme" şeklinde geçerken bu tarihten sonra kaleme alınan Clodius, J. Ch. (1729). Grammatica Turcica Necessariis regvlis praecipvas..., Donado, G. B. (1688). Della Letteraturade' Turchi, Osservationi..., Dombay, F. von (18.yy?). Proverbiorum Turcicorum Centuria..., Jaubert, P. A. (1823). Elements de la grammaire turke. ve Fleischer, H.F. (1853). Der vollkommene und schnelle...adlı eserlerde 'Kan eyleme, kanun eyle' şeklinde geçmeye başlamıştır.

Örnek 2.

(1612) Biberi tfchok ollan lahana da uftine cor. Biberi çok olan lahana da ustine kor.

(1632) Piberi chiok kasan[+an] lahana da ustine kor. Piberi çok kazanan lahana da ustine kor.

(18.yy?) Biberi çoḳ olan mercimek corbasına eker.

Atasözü; Megiser, H. (1612). Institutionum linguae turcicae libri quatuor... ve Montalbano ve G. B. (1632). Turcicae linguae per terminos... adlı eserlerde biberi çok olanın/kazananın lahana üstüne de koyacağı şeklinde geçerken Dombay, F. von (18.yy?). Proverbiorum Turcicorum Centuria... adlı eserinde biberi çok olanın mercimek çorbasına ekeceği şeklinde geçmektedir. 


\section{Sonuç}

16., 17., 18. ve 19. yüzyllda yazılmış 26 transkripsiyon metninde toplam 4461 atasözü tespit edilmiştir. 16. yüzylla ait 1 eserde 1 atasözü, 17. yüzylla ait 10 eserde 1637 atasözü, 18. yüzyıla ait 4 eserde 346 atasözü, 19. yüzylla ait 11 eserde 2477 atasözü vardır.

Atasözlerinin 1043’ü Latin harfleriyle, 2464'ü Arap harfleriyle, 954’ü de hem Arap hem de Latin harfli olarak verilmiştir. Arap harfleriyle verilen atasözlerinin diğerlerine göre çok olması yazarın atasözleri aracılığıyla hem Osmanlı Türkçesini öğretmeyi hem de Türklerin kültürleri hakkında bilgi vermeyi amaçladığını göstermektedir.

Transkripsiyon metinleri barındırdıkları malzemeler ve bunların ele alınış biçimleriyle yabancılara Türkçe öğretimi açısından örnek metinlerdir. Aynı zamanda içindeki atasözleri sayesinde atasözleri araştırmacıları için 16. yüzyıldan 20. yüzyıla kadar hangilerinin değişime uğradığını, hangilerinin ilk defa hangi yüzyılda örneklendiğini, hangilerinin zamanla unutulduğunu göstermesi açısından da önemli kaynaklardır.

\section{Kaynakça}

Aksulu, N. M. (1998). Mohaç Esiri Bartholomaeus Georgieviz (1505-1566) ve Türklerle İlgili Yazıları. Ankara: Kültür Bakanllğı.

Argunşah, M. ve Güner, G. (2015). Codex Cumanicus. İstanbul: Kesit

Clodius, J. Ch. (1729). Grammatica Tvrcica Necessariis regvlis praecipvas lingvae difficvltates illvstrans (etc). Lipsiae: Wolffgangvm Deer.

Dombay, F. von (18.yy?). Proverbiorum Turcicorum Centuria I-IV \& Proverbia Turcica Quadraginta. Ingiltere: Manchester John Rylands Kütüphanesi.

Donado, G. B. (1688). Della Letteratura de' Turchi, Osservationi fatte da Gio. Italia: per Andrea Poletti. all'insegna dell'Italia, a San Marco.

Donado, G. B. (1688). Raccolta curiosissima d'Adaggi Turcheschi trasportati dal proprio Idioma nell Italiano e Latino dalli Giovani di Lingua, sotto il Bailaggio in Constantinopoli dell' illustriss ed eccell. Italia: Per Andrea Poletti all' Italia.

Drimba, V. (1985). “XVII. Yüzyllda Yayımlanmış Bir Türk Atasözleri ve Vecizeleri Derlemesi”. Türk Dili Araştırmaları Yıllı Belleten. ss. 9-26. Ankara: TTK Yayınları.

Durmuş, O. (2017). Türkiye Türkçesinin Basılı İlk Atasözleri: H. Megiser'in Paroemiologia Polyglottos Adlı Eserinde Yer Alan Atasözleri. Vefatının20. Yllı Munasebetiyle Prof. Dr. Necmettin Hacıeminoğlu Hatıra Kitabı. İstanbul: Türk Edebiyatı Vakfı.

Ekinci, M. U. (2013). “Franz Von Dombay’nn (1758-1810) Türkçe Atasözleri ve Deyimler Derlemesi”. Türkbilig 2013/25 55-74.

Fink, L. (1872). Türkischer Dragoman, Grammatik, Phrasensammlung und Wörterbuch der türkischen Sprache. Leipzig: F.A. Brockhaus Verlag.

Fleischer, H.F. (1853). Der vollkommene und schnelle türkische Selbstlehrer. Wien: Albert A. Wenedikt Verlag.

Francesco, M. M. (1643). Syntagmaton Linguarum Orientalium quae in Georgiae regionibus audiuntur liber primus, complectens Georgianae, seu Ibericae vulgaris linguae institutiones grammaticas.: [with] Liber secundus complectens Arabum et Turcarum orthographiam ac Turcicae linguae institutiones. Stamperia della Sacra Congregazione de Propaganda Fide (Roma).

Gallotta, A. (1986). Latin Harfleri ile Yazılmış Birkaç Osmanlı Atasözü. İstanbul Üniversitesi Edebiyat Fakültesi Türk Dili ve Edebiyatı Dergisi. C. 24 ss. 235-249. 
Georgieuiz, B. (1544). De Tvrcarvm Ritv Et Caeremoiis. Antverpia.

Gül, B. (2006). Almanya'da Türkoloji Çalışmaları. Türkbilig 2006/11. ss.56-117.

Harsany, Jacobus Nagy de (1672). Colloquia Familiaria Turcico Latina Seu Status Turcicus Loquens. Coloniae Brandeburgicae.

Hindoglu, A. (1829). Theoretisch=pracktische Türkische Sprachlehre für Deutsche. Wien: Anton Edler v. Schmid.

Hrabskius, J. (1655). Proverbia quaedam Arabica, Persica, \& Turcica: In Gratiam Praedictarum Linguarum Cultorum Edita (Editör: Fincelius, Hiob Wilhelm). Witteberg: Wilhelm Fincelius.

Hrabskius, J. (1655). Proverbia quaedam Arabica, Persica, \& Turcica: In Gratiam Praedictarum Linguarum Cultorum Edita (Editör: Fincelius, Hiob Wilhelm). Witteberg: Wilhelm Fincelius.

İğci, A. (2014). 17. Yüzyılda Batı Rumeli Türkçesinin Özellikleri. Ege Üniversitesi Sosyal Bilimler Enstitüsü. İzmir. (Yayımlanmamış Doktora Tezi)

İğci, A. (2015). 1672 Tarihli Colloquia Familiaria Turcico Latina'da Tarihî Ağız Malzemesi ve Batı Rumeli Tarzı Fiil Çatısı. Diyalektolog Yaz 2015, Sayı 10, ss. 71-77.

Jan Schmidt (2011). A Catalogue of the Turkish Manuscripts in the John Rylands University Library at Manchester. Leiden: Brill.

Jaubert, P. A. (1823). Elements de la grammaire turke. Paris: Dundey-Dupre Pere et Fils.

Kaymaz, Z. (2013). Ermeni Harfli Bir Türkçe Atasözleri Kitabı. Türk Dünyası İncelemeleri Kitabı XIII/1 ss. $173-212$.

Kut, T. (1983). Ermeni Harfleriyle Basılmış Türkçe Atasözleri Kitapları. Türk Folkloru 53/5 ss. 5-6.

Mallouf, N. (1860). Guide en trois langues: Française, anglaise at Turque. Paris: Maisonneuve et Ce.

Megiser, H. (1605). Polyglottos: hoc est: Proverbia et Sententiae complurium linguarum. Ex Sacris Videlicet Hebraeorum fontibus, atq; ex optimis ac probatiffimis quibusq; Graecae \& Latinae linguae fcriptoribus, defumtae, \& in Locos Communes digeftae: \& cum Italorum, Hifpanorum, Gallorum, Germanorum, Belgarum, Sclavonum, Arabum, Turcarum denique aliarumq; Nationum fententiofis Proverbiis collatae. Lipsiae (Leipzig): Sumtibus Henningis Grosii.

Megiser, H. (1612). Institutionum linguae turcicae, libri quatuor. Quorum I. continet partem isagoges grammaticae Turcicae priorem, de orthographia Turco-Arabica. II. verò isagoges grammaticae Turcicae partem, poeteriorem, de etymologia Turcorum. III. complectitur diversa linguae Turcicae exercitia, \& duas proverbiorum Turcicorum centurias. IV. Dictionarium est Latino Turcicum \& vicissim Turcico Latinum. Lipsiae (Leipzig): Magiserus.

Montalbano, G. B. (1632). Turcicae linguae per terminos latinos educta Syntaxis in usum eorum qui in Turciam missiones subeunt ad nutum sacrae congregationis de propoganda fide. İtalya: Napoli Milli Kütüphanesi.

Müller A. (1889). Türkische Grammatik mit Paradigmen Litteratur Chrestomathie und Glossar. Berlin: H. Reuther's Verlagsbuchhandlung

Müller, A. (1889). Türkische Grammatik, mit Paradigmen, Litteratur, Chrestomathie, und Glossar. Berlin: H. Reuther

Pianzola, B. (1789). Dizionario, Grammatiche, e Dialoghi Per Apprendere le Lingue Italiana, GrecaVolgare, e Turca, e Varie Scienze. Podova: Fermo.

Piquere, P. J. (1869). Grammatik der türkisch-osmanischen Umgangssprache. Wien: Albert A. Wenedikt Verelag.

Preindl, J. von (1789). Grammaire Turque: D'une toute nouvelle methode d'apprendre cette langue en peu de semaines avec un vocabulaire. Berlin.

Schlechta Wssehrd, O. F. von (1865). Osmanische Sprichwörter. Wien: K.K. Orientalische Akademie

Schlechta Wssehrd, O. F. von (1865). Osmanische Sprichwörter. Wien: K.K. Orientalische Akademie. 
Timoteo, A. (1688). Proverbii utili, e virtuosi in lingua araba, persiana, e turca, gran parte in versi, con la loro ispiegatione in lingua latina, \& italiana et alcuni vocaboli di dette lingue. In Padova: Nella Stamperia del Seminario.

Vaughan, T. (1709). A Grammar Of The Turkish Language. London: Publisher, J. Humphreys.

Wahrmund, A. (1869). Praktisch Handbuch der osmanisch-türkischen Sprache I-III. Giessen: J. Ricker'sche Buchhandlung.

Wickerhauser, M. (1853). Wegweiser zum Verständnis der türkischen Sprache. Eine deutsch-türkische Chrestomathie. Wien: K.K. Hof-und Staatsdruckerei

Wickerhauser, M. (1853). Wegweiser zum Verständnis der türkischen Sprache. Eine deutsch-türkische Chrestomathie. Wien: K.K. Hof-und Staatsdruckerei.

Yllmaz, Y. - Demirci, O. (2016). Preindl’in Grammaire Turque’ünde Türk Atasözleri. Turkish Studies, 11(20), 25-40.

Ylldız, H. ve Öztürk Abdulkadir (2016). 19. Yüzylla Ait Ermeni Harfli Türkçe Atasözleri Üzerine. ODÜSOBIAD 6 (3) ss. 739-766.

? (1689?). "Proverbia turcica cum versione italica et latine" \& "Iterum Proverbia turcica, quorum major pars latinis literis scripta est”. (Eserin sahibi: Moritz Georg Weideman). 